\title{
Miltefosine: A Miracle Drug for Meningoencephalitis Caused by Free-Living Amoebas
}

\author{
Ammar Alli ${ }^{1,2}$, Juan Fernando Ortiz ${ }^{3,4}$, Álvaro Morillo Cox $^{5}$, Maria Armas ${ }^{6}$, Victor A. Orellana ${ }^{7}$ \\ 1. Internal Medicine, Tishreen University Faculty of Medicine, Lattakia, SYR 2. Internal Medicine, Universitat de \\ Barcelona, Barcelona, ESP 3. Neurology, Universidad San Francisco de Quito, Quito, ECU 4. Neurology, Larkin \\ Community Hospital, Miami, USA 5. Medicine, Universidad San Francisco de Quito, Quito, ECU 6. Surgery, Pontificia \\ Universidad Catolica del Ecuador, Quito, ECU 7. Obstetrics and Gynecology, Pontifica Universidad Católica del Ecuador, \\ Quito, ECU
}

Corresponding author: Juan Fernando Ortiz, sumjuanfer41@gmail.com

\begin{abstract}
Meningoencephalitis caused by free-living amoebas (FLA) has a high mortality rate, and most treatments are ineffective. FLA includes Naegleria, Fowleri, Acanthamoeba, and Balamuthia mandrillaris (M). We explore the use of miltefosine in the treatment of one of these infections. The concerning mortality of the infection obligates us to look for more effective treatments for meningoencephalitis caused by FLA. During this review, we will consolidate the knowledge of using miltefosine in these three infections. We will investigate the mechanism by which the drug is effective in these infections as well. After this comprehensive review, we should assess if miltefosine improves the mortality and prognosis of the infection with the information collected. We used a Medical Subject Headings (MeSH) search on PubMed. Inclusion criteria included papers written in the English language and human subjects research for the past 25 years. Until today, there are no definitive guidelines to be followed when treating such patients. However, miltefosine has demonstrated promising results. Miltefosine decreases the usual mortality rate in the three infections; however, there are few reports due to the low frequency of these infections. Almost all cases we documented have survived. More information needs to be gathered for the use of miltefosine for these infections.
\end{abstract}

Review began 02/27/2021 Review ended 02/28/2021 Published 03/04/2021

(๑) Copyright 2021 Alli et al. This is an open access article distributed under the terms of the Creative Commons Attribution License CC-BY 4.0., which permits unrestricted use, distribution, and reproduction in any medium, provided the original author and source are credited.
Categories: Neurology, Infectious Disease

Keywords: free living amoebas, meningoencephalitis

\section{Introduction And Background}

Naegleria causes primary amebic meningoencephalitis (PAM). The parasite lives in temperatures above 30 degrees and can tolerate temperatures up to 45 degrees. The most common risk factor in developing the infection is participating in recreational water activities. Approximately 300 cases have been reported worldwide [1]. Inhalation of infected water leads to the involvement of the olfactory bulb. Extra central nervous system (CNS) infection also has been reported [1]. In a CDC report, 79\% of cases were male, and infections occurred mainly in the July-September period in the southern states [2]. For PAM, the median time from exposure to death is 9.9 days [3]. In a report of 111 cases, mortality was $99 \%$ [3]. The main symptoms of the disease are neurological. In the end, the disease presents rapid deterioration with profound mental alteration and severe intracranial hypertension leading to herniation and death a few days after the onset of symptoms [4]. The diagnosis begins by having a high level of suspicion related to the exposure and the patient's rapid clinical deterioration. The key is to perform a lumbar puncture with cerebrospinal fluid (CSF) analysis by a phase-contrast microscope is beneficial to ameba visualization. Giemsa or trichrome stains help define morphology features [5].

Acanthamoeba causes granulomatous amebic encephalitis (GAE), mainly among immunocompromised patients; however, immunocompetent cases have also been reported [6]. The transmission mode includes the inhalation of the cyst through the respiratory tract or direct contact with the skin followed by hematogenous spread. The parasite is usually located in environments with rich biofilms like sewage, heating hospital environments, dental and dialysis units, and contact lenses [7]. Approximately 150 cases have been reported worldwide [8]. The median time from exposure to death is eight days to a few months and the mortality rate ranges from $97 \%$ to $98 \%$ [6]. The clinical signs and symptoms of GAE are headaches, neck stiffness, confusion, gait ataxia, irritability, hemiparesis, diplopia, photophobia, and cranial nerve palsies [9]. Clinical suspicion and history are needed to confirm the diagnosis. Contrary to PAM, lumbar puncture with CSF may not show trophozoites due to the encysted nature and brain biopsy may be needed. The CSF shows mild lymphocytic pleocytosis, elevated protein, and low glucose. Trophozoites are rarely seen in CSF because of their encysted nature. However, Giemsa stain could show the trophozoites [10]. In the hematoxylin and eosin (H\&E) stain of fixed preparation of CSF, acanthamoeba trophozoites is visualized, which may also indicate trophozoites [9].

Balamuthia mandrillaris (M) causes GAE. It can be isolated from soil, dust, and water [11]. It preferably 
affects immunocompromised patients but also affects the immunocompetent [4]. Currently, 200 cases have been reported, predominantly in the United States and South America. Hispanic patients appeared to be more affected due to possible genetic susceptibility and environmental exposure. The infection seems to be more common in males [11]. The course toward a fatal outcome since the onset of neurologic symptoms is two to 12 weeks if untreated. The mortality rate is around 95\% [4]. The clinical features include neurological and dermatological findings. Patients present with annular, nonulcerated, and infiltrative plaques in the central face over the nose. The main neurological finding is thrombotic angiitis, which leads to infarction, hemorrhage, and necrosis. Other neurological signs included unilateral headaches, regression, focal seizures, and cranial nerve dysfunction. Patients can present with localized motor deficits followed by meningeal signs and elevated intracranial pressure. Finally, patients evolve to a progressive loss of consciousness $[4,11]$. To diagnose these infections, we must have clinical suspicion based on a history of neurologic findings and dermatological findings. While presentations may be different, overall, they have similar central nervous system (CNS) symptoms. Histopathology of the skin affection reveals a diffuse granulomatous reaction in the reticular dermis, granulomas, an infiltrate rich in plasma cell and lymphocytes, and abundant giant cells inside and outside the granulomas [12-13]. Visualization of a trophozoite is required for definitive diagnosis in $60 \%-75 \%$ of cases. Direct immunofluorescence or immunoperoxidase staining must be performed if possible [13]. Additionally, a new polymerase chain reaction (PCR) technique for the detection of amebic deoxyribonucleic acid (DNA) has been recently introduced [12-13]

Table 1 shows the main epidemiological, clinical, and diagnostic features of free-living amoebas [1-13]. 


\section{Cureus}

\begin{tabular}{|c|c|c|c|}
\hline & Naegleria & Acanthamoeba & Balamuthia \\
\hline Epidemiology & $\begin{array}{l}\text { Lives on surfaces with rich biofilm. } \\
\text { Risk factors: hematological } \\
\text { malignancies, diabetes mellitus, } \\
\text { prolonged use of antibiotics, } \\
\text { immunosuppressive state. } \\
\text { Approximately } 150 \text { cases have } \\
\text { been reported worldwide. There is } \\
\text { no sex predominance }\end{array}$ & $\begin{array}{l}\text { Lives in temperatures above } 30 \\
\text { degrees. Most common risk } \\
\text { factor: participation in } \\
\text { recreational water activities, } \\
\text { approximately } 300 \text { cases have } \\
\text { been reported worldwide. Males } \\
\text { predominantly infected }\end{array}$ & $\begin{array}{l}\text { Risk factors: immune-compromised Hispanic origin } \\
\text { due to genetic susceptibility and environmental } \\
\text { exposure. Approximately } 109 \text { cases reported } \\
\text { worldwide. Male predominance }\end{array}$ \\
\hline $\begin{array}{l}\text { Median time } \\
\text { from } \\
\text { exposure to } \\
\text { death }\end{array}$ & Eight days to several months & 9.9 days & Weeks to years \\
\hline Mortality & $97 \%-98 \%$ & $99 \%$ & $95 \%$ \\
\hline $\begin{array}{l}\text { Clinical } \\
\text { features }\end{array}$ & $\begin{array}{l}\text { Headaches, neck stiffness, ataxia, } \\
\text { irritability, photophobia, diplopia, } \\
\text { hemiparesis, cranial nerve palsies, } \\
\text { and increased ICP }\end{array}$ & $\begin{array}{l}\text { Headaches, behavior } \\
\text { abnormalities, neck stiffness, } \\
\text { ataxia, irritability, photophobia, } \\
\text { diplopia, high fever, meningeal } \\
\text { signs, cranial nerve palsies, } \\
\text { seizures, encephalitis, increased } \\
\text { ICP, and keratitis }\end{array}$ & $\begin{array}{l}\text { Headaches, behavior abnormalities, neck stiffness, } \\
\text { ataxia, irritability, photophobia, diplopia, high fever, } \\
\text { meningeal signs, cranial nerve palsies, seizures, } \\
\text { encephalitis, increased ICP, and skin manifestations } \\
\text { followed by a neurological compromise in weeks or } \\
\text { months. The skin signs are: annular, non-ulcerated, } \\
\text { infiltrative, asymptomatic plaque in the central face } \\
\text { over the nose }\end{array}$ \\
\hline Diagnosis & $\begin{array}{l}\text { Microscopic findings reveal } \\
\text { granulomas with multinucleated } \\
\text { giant cells. Specific antibodies to } \\
\text { different species of } \\
\text { Acanthamoeba along with } \\
\text { immunofluorescent staining can } \\
\text { also be used. }\end{array}$ & $\begin{array}{l}\text { CSF examination by the phase- } \\
\text { contrast microscope is beneficial } \\
\text { for ameba visualization of } \\
\text { Giemsa or trichrome stains help } \\
\text { to define morphology features }\end{array}$ & $\begin{array}{l}\text { Recognition of the cutaneous and CNS findings. } \\
\text { Visualization of the parasite is required for definitive } \\
\text { diagnosis and is acquired by biopsy }\end{array}$ \\
\hline Imaging & $\begin{array}{l}\text { On CT/MRI, both enhancing and } \\
\text { non-enhancing lesions can be } \\
\text { seen. There are also multifocal } \\
\text { areas of signal intensity or } \\
\text { discrete lesions that may be seen, }\end{array}$ & $\begin{array}{l}\text { CT scan and MRI findings are } \\
\text { nonspecific. However, brain } \\
\text { edema, hydrocephalus, basilar } \\
\text { meningeal enhancement, and } \\
\text { infarctions are described. These } \\
\text { lesions are found on the frontal } \\
\text { and temporal lobes, cerebellum, } \\
\text { and spinal cord }\end{array}$ & $\begin{array}{l}\text { Multiple lesions from small and solid to large and } \\
\text { nodular lesions with ring enhancement surrounding } \\
\text { vasogenic edema and regional mass effect may be } \\
\text { present as intralesional hemorrhage, lesions can } \\
\text { compromise both white and gray matter. }\end{array}$ \\
\hline CFS Findings & $\begin{array}{l}\text { Glucose: Low/Protein: High/CSF } \\
\text { pressure: increased, Cells: } \\
\text { pleocytosis with abundant } \\
\text { lymphocytes and } \\
\text { polymorphonuclear leukocytes }\end{array}$ & $\begin{array}{l}\text { Glucose: Low/Protein Hiigh CSF } \\
\text { pressure: increased/Cells: } \\
\text { pleocytosis with abundant } \\
\text { lymphocytes and } \\
\text { polymorphonuclear leukocytes. } \\
\text { Also red cells }\end{array}$ & $\begin{array}{l}\text { Glucose: Normal to low/Protein: Normal to } \\
\text { elevated/CSF pressure: Increased/cells: pleocytosis } \\
\text { with abundant lymphocytes and polymorphonuclear } \\
\text { leukocytes }\end{array}$ \\
\hline $\begin{array}{l}\text { Empiric } \\
\text { Treatment }\end{array}$ & $\begin{array}{l}\text { Initial dose of amphotericin B (IV) } \\
\text { for three days, followed by } \\
\text { amphotericin B (IV) with a smaller } \\
\text { quantity for } 14 \text { days. Then, a } \\
\text { regimen of azithromycin (IV/PO), } \\
\text { rifampin (IV/PO), miltefosine, } \\
\text { (IV/PO and dexamethasone (IV) }\end{array}$ & $\begin{array}{l}\text { Pentamidine (PO), Sulfadiazine } \\
\text { (PO), Flucytosine (PO), } \\
\text { Fluconazole (PO or IV), } \\
\text { miltefosine (PO), and } \\
\text { azithromycin (PO). The duration } \\
\text { of the treatment has not been } \\
\text { established }\end{array}$ & Optimal treatment is uncertain \\
\hline
\end{tabular}

\section{TABLE 1: Clinical features of free-living amoebas}

CSF: cerebrospinal fluid; ICP: increased intracranial pressure; CNS: central nervous system

As mentioned before, these infections are mostly fatal, with mortality rates ranging from $95 \%-99 \%[1,6,11]$. These concerning numbers demand that research be done to look for treatments that lower mortality rates. 


\section{Cureus}

Lately, the drug miltefosine has been shown to reduce the growth of amoeba and eliminate the drug in vitro studies. This paper aims to review the reports where miltefosine has been used to determine if adding miltefosine decreases the fatality rate. During this review, we aim to consolidate the knowledge of miltefosine use in treating these infections. Also, we aim to investigate the efficacy of the drug and develop a comprehensive overview of the latest miltefosine use in treating these infections

\section{Review}

\section{Methods}

We used a medical subject strategy (MeSH) in PubMed for the realization of this paper. We included articles published in the last 20 years, in the English Language, and conducted on humans. We excluded literature reviews, systematic reviews, and meta-analyses from the discussion of this publication.

Table 2 shows the combination of MeSH terms used to discuss this article and the number of articles found with each MeSH term combination.

\begin{tabular}{|l|c|}
\hline Search Term & Papers extracted \\
\hline ("miltefosine" [Supplementary Concept]) AND "Balamuthia"[Mesh] & 1 \\
\hline ("miltefosine" [Supplementary Concept]) AND "Acanthamoeba"[Mesh] & 2 \\
("miltefosine" [Supplementary Concept]) AND "Naegleria fowleri"[Mesh] & 9 \\
(miltefosine[Title/Abstract]) AND (naegleria[Title/Abstract]) & 23 \\
(miltefosine[Title/Abstract]) AND (balamuthia[Title/Abstract]) & 13 \\
(miltefosine[Title/Abstract]) AND (acanthomoeba[Title/Abstract]) & 44
\end{tabular}

\section{TABLE 2: Methods of the study}

MeSH: medical subject subheading

\section{Results}

We initially screened 102 publications. After applying the inclusion and exclusion criteria, we had 92 papers. We excluded 14 more papers because either the data could not be extracted or the paper was not relevant for our objectives or study outcomes. We exclude papers that were literature reviews, systematic reviews, or meta-analyses and ended up with 52 papers.

Table 3 shows the results of the study.

\begin{tabular}{|l|c|}
\hline MeSH term combination & Number of articles \\
\hline Initial recollection of information & 102 \\
\hline Paper published in English & 92 \\
\hline Paper published after 2010 & 78 \\
\hline Exclusion of reviews, systematic reviews, and meta-analyses & 52 \\
\hline
\end{tabular}

\section{TABLE 3: Results of the study}

MeSH: medical subject heading

After applying the inclusion and exclusion criteria, we excluded papers that did not meet our objectives or were duplicates and ended up with 24 papers for the discussion (not including the introduction) of this paper.

\section{Discussion}


First, a historical review of the drug miltefosine is given. Then, the drug's role is analyzed in the treatment of the three FLA (Naegleria, Balamuthia, and Acanthoamabe) meningoencephalitis. The main points to review are the in vitro studies, animal studies, and studies conducted on humans.

\section{Milfetosine Historical Review}

Miltefosine was implemented in 1980 as an experimental antineoplastic agent for breast cancer [14]. Moreover, in 2002, it was used as an antiparasitic for a case of visceral leishmaniasis [2]. In 2013, the CDC started recommending miltefosine for the treatment of PAM. Later, in 2014, the Food and Drug Administration (FDA) authorized its use in Leishmaniasis's treatment in patients over 12 years of age. Additional therapeutic benefits have been reported in American and African trypanosomiasis [14-15]. The precise mechanism of action is not entirely understood. Still, it is known that the phospholipid structure and alkyl phosphocholine compound allow the drug to penetrate the blood-brain barrier and concentrate in brain tissue [14-15]. Miltefosine is usually well-tolerated, except for gastrointestinal complaints, nephrotoxicity has also been described [16].

Miltefosine Use in Primary Amoebic Meningoencephalitis

Naegleria causes a robust inflammatory response causing lytic necrosis and hemorrhage [17]. The CDC had reported the use of miltefosine in 26 cases by 2013 [16]. The drug of choice for PAM is amphotericin B for its clinical efficacy. Amphotericin has been used in all reported survivors of PAM [14]. However, the drug has high toxicity levels, so there has been an effort to find new drug alternatives [18]. An in-vitro study compared amphotericin B and miltefosine for a month. The drug's minimal inhibitory concentration (MIC) was 0.78 and $0.25 \mathrm{ug} / \mathrm{ml}$ for amphotericin and miltefosine, respectively. There were higher survival rates for miltefosine (55\%) as compared to amphotericin B (40\%) [15].

It is not known how the dose, frequency, and intervals of administration affect successful treatment. However, there is consensus on a maximum amount of $50 \mathrm{mg}$ tablets: $2.5 \mathrm{mg} / \mathrm{kg} / \mathrm{day}$. The treatment period varies from case to case [17,19].

Cases Documenting the Use of Miltefosine in Primary Amoebic Meningoencephalitis

Cope and Dunn reported one and two cases, respectively. Between the three cases, there were two survivors and one death where miltefosine was used. One case had a total functional recovery, the other had chronic neurological manifestation, and the third one died of brain death [18,20].

In another report, a man with no comorbidities presented with a two-day history of fever, worsening headache, and generalized weakness. Neurologic focal deficits were absent. The diagnosis of PAM was made within 24 hours. The CDC guideline was implemented on the first day. On day three, he developed diabetes insipidus (DI) and died four days later with cardiac arrest. Muhammad et al. suggest that the mechanism behind DI in patients with PAM needs to be taken into account regarding the treatment approach in these patients [21].

Two cases mimicked flu-like illness on initial presentation and received supportive care followed by discharge. Meningoencephalitis signs and deleterious neurologic complications developed on the second presentation, followed by early death despite implementing aggressive measures and following the CDC guidelines. Stowe et al. suggest that early diagnosis and assessment of host susceptibility factors should be taken into account for adequate treatment strategies [22]. The following case reports (Table 4 ) describe the application of miltefosine on second-line use [18,20-22]. 


\begin{tabular}{|c|c|c|c|c|c|c|c|}
\hline Reference & $\begin{array}{l}\text { Case } \\
\text { (age, } \\
\text { sex) }\end{array}$ & $\begin{array}{l}\text { Diagnosis } \\
\text { from } \\
\text { symptoms } \\
\text { onset }\end{array}$ & Initial treatment ${ }^{1}$ & $\begin{array}{l}\text { Miltefosine } \\
\text { initiation from } \\
\text { diagnosis }\end{array}$ & $\begin{array}{l}\text { Total } \\
\text { days of } \\
\text { treatment }\end{array}$ & Outcome & Follow up \\
\hline [18] & $\begin{array}{l}\text { 12-year- } \\
\text { old, } \\
\text { female }\end{array}$ & two days & AmB, Rif, Flu, AZM, Dex & 36 hours & 55 days & Survive & $\begin{array}{l}\text { Full recovery after three } \\
\text { months, with speech and } \\
\text { physical therapy }\end{array}$ \\
\hline [20] & $\begin{array}{l}\text { 12-year- } \\
\text { old, } \\
\text { male }\end{array}$ & one day & $\begin{array}{l}\text { Acy, liposomal AmB, Rif, Flu, } \\
\text { Van, CFX, IV Deoxy AmB, Flu, } \\
\text { AZM, Rif }\end{array}$ & 31 hours & 16 days & Dead & $\begin{array}{l}\text { Braindead on hospital } \\
\text { day } 16\end{array}$ \\
\hline [20] & $\begin{array}{l}\text { Eight- } \\
\text { year- } \\
\text { old, } \\
\text { male }\end{array}$ & five days & AmB, Rif, Flu, AZM, Dex & $\begin{array}{l}14 \text { hours from } \\
\text { ICU admission }\end{array}$ & 39 days & Survive & $\begin{array}{l}\text { Significant neurological } \\
\text { deficits }\end{array}$ \\
\hline [21] & $\begin{array}{l}\text { 44-year- } \\
\text { old male }\end{array}$ & four days & IV/IT AmB, Flu, Rif, Dex & Within 24 hours & four days & Dead & $\begin{array}{l}\text { Diabetes Insipidus on } \\
\text { day three, Cardiac arrest } \\
\text { on day four }\end{array}$ \\
\hline [22] & $\begin{array}{l}\text { 4-year- } \\
\text { old male }\end{array}$ & for - five days & $\begin{array}{l}\text { LOR, Phos AZM, AmB, Rif, Flu, } \\
\text { Dex }\end{array}$ & $24-48$ hours & two days & Dead & $\begin{array}{l}\text { Braindead on hospital } \\
\text { day two }\end{array}$ \\
\hline [22] & $\begin{array}{l}\text { 14-year- } \\
\text { old male }\end{array}$ & $\begin{array}{l}\text { three - five } \\
\text { days }\end{array}$ & $\begin{array}{l}\text { Van, CFX, Flu, AZM, Rif, IV/IT } \\
\text { AmB }\end{array}$ & 24 - 92 hours & four days & Dead & $\begin{array}{l}\text { Brain herniation, later } \\
\text { braindead on hospital } \\
\text { day four }\end{array}$ \\
\hline
\end{tabular}

\section{TABLE 4: Milfetosine use in primary amoebic meningoencephalitis}

AmB: amphotericin B, Rif: rifampin, Flu: fluconazole, AZM: azithromycin, Dex: dexamethasone, Acy: acyclovir, Van: vancomycin, CFX: ceftriaxone, Deoxy AmB IV: deoxycholate amphotericin B intravenously, ICU: intensive care unit

All three patients reported received miltefosine as a second-line drug in their treatment regimen. For such, the outcomes evidently vary from survival with full neurologic recovery, survival with neurological deficits, and death. Two of three patients survive with miltefosine use as compared to three out of nine PAM fatal cases without miltefosine (unpublished reports of the CDC) [18]. Miltefosine's survival advantage depends on its accessibility, availability, and time management. Furthermore, successful recovery is associated with early diagnosis and a prompt establishment of a combination of antimicrobials plus measures to control elevated intracranial pressure [20].

The use of miltefosine looks potentially attractive in the battle against PAM. From its feasible oral administration, its ability to readily accumulate on CSF at amebicidal concentrations with low toxicity offers an advantage over other medications' limitations. At any suspicion of PMA, the CDC should be contacted to consult with an FLA expert for diagnosis assistance, sample collection guidance, and recommendations regarding treatment, including the use of miltefosine [16].

Miltefosine Use in Granulomatous Amebic Encephalitis (Acanthamoeba)

Acanthamoeba causes GAE. In vitro studies explored miltefosine's effect on three strains of Acanthamoeba: sp, lugdunensis, and castellani. Acanthamoeba castellanii had the highest sensitivity, with about 100\% eradication of trophozoites at $62.5 \mathrm{mM}$ after 24 hours [23]. In comparison, the other two strains of Acanthamoeba sp and Acanthamoeba lugdunensis showed resistance even at high concentrations [23].

Topical miltefosine was studied on Syrian hamsters to test its efficacy in treating keratitis. Keratitis due to Acanthamoeba is a painful, life-threatening condition that usually affects immunocompromised patients [24]. At the end of the trial, $85 \%$ of corneas treated with miltefosine became cured versus $65 \%$ of the other treatment (propamidine isethionate plus polyhexanide) [24].

Cases Documenting the Use of Miltefosine in Granulomatous Amebic Encephalitis (Acanthamoeba)

In a case report, a 60-year-old woman with rhinorrhea and sinus pressure five months after heart transplantation was treated with ampicillin-sulbactam [25]. On MRI, a raised right nasal septal mass was discovered. The mass was resected and sent for histological examination, revealing the diagnosis of GAE 
[25]. The infection spread to the skin, sinuses, and bones. Initial therapy was amphotericin B and metronidazole for four days [25]. On day four, the regimen switched to a combination of fluconazole, flucytosine, and miltefosine [25]. Six months after treatment, the lesions resolved, and miltefosine was discontinued eight months after discharge [25]. The patient had a complete recovery.

In a second case report, a 25-year-old immunocompromised man from India developed GAE. The patient also had tuberculous meningitis [26]. The patient was treated with a mixture of miltefosine, amikacin, and four more tuberculostatic drugs. Topical miltefosine cured the skin lesions in six weeks, and it was discontinued after two more additional weeks [26]. Intrathecal amikacin and oral miltefosine were stopped after six and eight weeks, respectively [26]. The patient was eventually discharged for recovery of lesions.

In another report, a 38-year-old man presented with tinnitus for three days before developing a generalized seizure [27]. On CT, a right temporal lobe was found. Several months later, serologic studies consistent with Acanthamoeba came back positive [27]. The patient was admitted to the hospital and administered a combination of miltefosine and voriconazole. The patient fully recovered after he underwent surgical debunking of the mass and a combination of voriconazole and miltefosine for three months [27].

A case report of a 35-year-old man with acquired immunodeficiency syndrome (AIDS) (CD4 lymphocyte count of 30 cells $/ \mu \mathrm{l}$ ) was diagnosed with GAE on biopsy after MRI imaging showed multiple ring-enhancing lesions with hemorrhages [28]. The patient was started on a combination of miltefosine, fluconazole, albendazole, azithromycin, rifampin, and trimethoprim-sulfamethoxazole [28]. Later, he was surgically intervened but eventually died.

A 35-year-old man complained of recent onset of speech disturbance, gait instability, and a sudden onset of left hemiparesis [29]. MR imaging revealed an inhomogeneous contrast-enhancing right cerebellar lesion [29]. A tumor was suspected, and the patient was started on a steroid for two weeks before surgery. The patient's condition deteriorated. After confirming his diagnosis with a biopsy, he was treated with fluconazole, trimethoprim-sulphamethoxazole, and miltefosine [29]. The latter was discontinued later for gastrointestinal intolerance. After seven months of treatment, the patient was cured. The author argues that miltefosine only plays a marginal role in treating the infection because of the short duration that the drug was given [29].

A 63-year-old man presented to the emergency department with signs of encephalitis. He received a renal transplant six months ago and was immunocompromised with mycophenolate and tacrolimus [30]. Brain MRI showed intracranial masses in the left frontal lobe and left posterior temporal-occipital with edema [30]. The diagnosis was confirmed with a biopsy on day nine. So, he started with a combination of sulfadiazine, fluconazole, flucytosine, azithromycin, and miltefosine for treatment [30]. His condition continued to deteriorate, and he passed away during his fifth-week post-admission.

Table 5 details the cases of miltefosine use and Acanthamoeba [25-31] 


\begin{tabular}{|c|c|c|c|c|c|c|c|}
\hline Reference & $\begin{array}{l}\text { Case } \\
\text { (age, } \\
\text { sex) }\end{array}$ & $\begin{array}{l}\text { Diagnosis } \\
\text { from } \\
\text { symptoms to } \\
\text { onset }\end{array}$ & Initial treatment & $\begin{array}{l}\text { Miltefosine } \\
\text { Initiation from } \\
\text { diagnosis }\end{array}$ & treatment & Outcome & Follow-up \\
\hline [25] & $\begin{array}{l}\text { years, } \\
\text { female }\end{array}$ & 20 days & $\begin{array}{l}\text { AmB, metronidazole and } \\
\text { surgical resection }\end{array}$ & $\begin{array}{l}\text { Hospital day } \\
\text { four }\end{array}$ & $\begin{array}{l}\text { Six months for } \\
\text { resolution of lesions }\end{array}$ & Survived & $\begin{array}{l}\text { Full recovery with } \\
\text { eight months of } \\
\text { therapy to prevent } \\
\text { relapse }\end{array}$ \\
\hline [26] & $\begin{array}{l}25 \\
\text { years, } \\
\text { male }\end{array}$ & Six weeks & $\begin{array}{l}\text { TB regimen, surgical excision, } \\
\text { and amikacin }\end{array}$ & $\begin{array}{l}12 \text { weeks after } \\
\text { tuberculosis s } \\
\text { therapy }\end{array}$ & $\begin{array}{l}\text { Six weeks of } \\
\text { amikacin, eight } \\
\text { weeks of miltefosine }\end{array}$ & Survived & $\begin{array}{l}\text { Two years follow } \\
\text { up without relapse }\end{array}$ \\
\hline [27] & $\begin{array}{l}38 \\
\text { years, } \\
\text { male }\end{array}$ & Months later & $\begin{array}{l}\text { Voriconazole, plus surgical } \\
\text { excision }\end{array}$ & Months & Three months & Survived & $\begin{array}{l}\text { Information not } \\
\text { found }\end{array}$ \\
\hline [28] & $\begin{array}{l}35, \\
\text { male }\end{array}$ & Iwo weeks & $\begin{array}{l}\text { Miltefosine, fluconazole, } \\
\text { albendazole, azithromycin, } \\
\text { rifampin, and TMX }\end{array}$ & 10 days & Four weeks & Died & $\begin{array}{l}\text { He was surgically } \\
\text { intervened, but, } \\
\text { eventually, died }\end{array}$ \\
\hline [29] & male & Years & $\begin{array}{l}\text { HAART, fluconazole, TMX, and } \\
\text { miltefosine }\end{array}$ & Day 13 & $\begin{array}{l}\text { Seven days because } \\
\text { of gastrointestinal } \\
\text { intolerance }\end{array}$ & Survived & $\begin{array}{l}\text { After seven } \\
\text { months, he } \\
\text { eventually } \\
\text { recovered from the } \\
\text { infection }\end{array}$ \\
\hline [30] & male & Iwo weeks & $\begin{array}{l}\text { Dex, surgıcal excisıon, } \\
\text { sulfadiazine, fluconazole, } \\
\text { flucytosine, and azithromycin }\end{array}$ & 10 days & Four weeks & Died & $\begin{array}{l}\text { Died due to } \\
\text { declining kidney } \\
\text { function and } \\
\text { pancytopenia }\end{array}$ \\
\hline
\end{tabular}

\section{TABLE 5: Case report of a patient with meningoencephalitis due to GAE}

AmB: amphotericin B, TB: tuberculosis, GAE: granulomatous amebic encephalitis

In summary, six case reports where miltefosine was used for Acanthoamoeba were included in this review: five of them survived and two of them died. Even the delayed initiation of miltefosine did not seem to impact the outcome of treatment. The only case that succumbed to death was due to coexisting comorbidities. Miltefosine seemed to be the turning point in the treatment of GAE caused by Acanthamoeba.

Miltefosine Use in Granulomatous Amebic Encephalitis (Balamuthia)

In summary, six case reports of Acanthamoeba were included in this review: five survived, and only one died. Even the delayed initiation of miltefosine didn't seem to impact the outcome of treatment. The only case that succumbed to death was due to coexisting comorbidities. Miltefosine seemed to be the turning point in the treatment of GAE caused by Acanthamoeba.

In the in-vitro studies of miltefosine on Balamuthia, concentrations over $40 \mathrm{mM}$ cause protozoal cell lysis [15]. The mechanism by which the drug killed the parasites was through to be apoptosis [15]. Nonetheless, other reports described that miltefosine also has amoebastatic activity against Balamuthia. In that report, miltefosine inhibited in vitro growth by $90 \%$ [15]. Another in vitro study focused on the efficacy of various drugs against FLA, including an analysis of miltefosine against Balamuthia. In this study, other drugs were less effective as compared to miltefosine [32].

The combination of miltefosine, fluconazole, and albendazole is used in most successful cases of Balamuthia's treatment cases. In these cases, it's difficult to determine whether the beneficial outcomes were due to individual or synergistic effects of the drugs used in combinations, which warrants the need for more in vitro sensitivity studies for the medications in question.

Diminazene aceturate, a drug used in African human Trypanosomiasis, was the most effective in vitro. Nevertheless, the drug has significant side effects like polyneuritis, which limits the use in humans [32]. 
A 21-year-old woman had four years of cutaneous lesions consistent with cutaneous Balamuthia before hospital admission. The patient received many combinations of treatments that included: fluconazole, clotrimazole, and topical steroids for one year, followed by trimethoprim-sulfamethoxazole, fluconazole, and clarithromycin for eight months [33]. After several more regimens, the patient received a combination of fluconazole, albendazole, and miltefosine. After one year of treatment, magnetic resonance imaging confirmed the disappearance of the intracranial mass [33].

In another case, a 26-year-old Hispanic male presented to the emergency department with symptoms consistent with GAE. He was first treated with high-dose dexamethasone and albendazole for suspicion of neurocysticercosis [34]. He then underwent a brain biopsy and was diagnosed with GAE caused by Balamuthia on the third week of treatment miltefosine. The patient completed 114 combination therapy, including miltefosine, trimethoprim-sulfamethoxazole, azithromycin, and fluconazole [34]. The patient's discharge was approved after the resolution of lesions on MRI [34].

In a case report, a 69-year-old woman was admitted to the hospital for a decreased level of consciousness that started three days before. The woman was HIV negative, but her total CD4+ was 250/ $\mathrm{mm}^{3}$ [35]. Neuroimaging showed a centrally cavitary lesion in the right frontal lobe, left basal ganglia, and left cerebellar hemisphere [35]. She received IV dexamethasone and underwent craniotomy. The biopsy confirmed GAE by Balamuthia. She received a six medication-regimen of pentamidine, sulfadiazine, azithromycin, fluconazole, flucytosine, and miltefosine [35]. On the third hospital day, she had an ischemic stroke and deteriorated and was moved to hospice care, where she died a few weeks later [35].

Finally, in another case report, an 11-year-old boy of Hispanic ethnicity was hospitalized after three weeks of nausea, vomiting, lethargy, and right-sided weakness that caused him to fall one day before he was admitted to the hospital [36]. The patient was suffering from neurological symptoms for the past few months as well. The patient was sent for an MRI on day one of admission, and a tumor was suspected. On biopsy and H\&E stain, trophozoites were present [36]. Therefore, he was diagnosed with GAE, and treatment was started on day three [36]. The patient was placed on miltefosine on day seven, which is when he started showing improvements. However, by day 20, he started having new lesions and his condition began to deteriorate [36]. Miltefosine was stopped on day 34. On day 61, he was pronounced dead [36].

Table 5 details the cases of miltefosine use and Balamuthia [33-36].

\begin{tabular}{|c|c|c|c|c|c|c|c|}
\hline Reference & $\begin{array}{l}\text { Case } \\
\text { (age, } \\
\text { sex) }\end{array}$ & $\begin{array}{l}\text { Diagnosis } \\
\text { from } \\
\text { symptom to } \\
\text { onset }\end{array}$ & Initial treatment & $\begin{array}{l}\text { Miltefosine } \\
\text { initiation from } \\
\text { diagnosis }\end{array}$ & $\begin{array}{l}\text { Total } \\
\text { days of } \\
\text { treatment }\end{array}$ & Outcome & Follow-up \\
\hline [33] & $\begin{array}{l}21, \\
\text { female }\end{array}$ & Four months & $\begin{array}{l}\text { Fluconazole, clotrimazole, topical } \\
\text { steroid, fluconazole and clarithromycin, } \\
\text { TMP-SMX, albendazole }\end{array}$ & $>$ two years & one year & Survived & $\begin{array}{l}30 \text { months of } \\
\text { treatment including } 12 \\
\text { months without } \\
\text { therapy or recurrence }\end{array}$ \\
\hline [34] & $\begin{array}{l}26, \\
\text { male }\end{array}$ & Two months & Dex, albendazole, Azm, Flu,TMP-SMX & Third week & 114 days & Survived & $\begin{array}{l}\text { Continued nine } \\
\text { months of treatment } \\
\text { minus miltefosine }\end{array}$ \\
\hline [35] & $\begin{array}{l}69, \\
\text { female }\end{array}$ & Three days & $\begin{array}{l}\text { Azm, Flu, 5-FC, Sulfadiazine, } \\
\text { pentamidine }\end{array}$ & On 3rd day & $\begin{array}{l}\text { Three } \\
\text { days }\end{array}$ & Died & $\begin{array}{l}\text { A few weeks after } \\
\text { transfer to hospice } \\
\text { care }\end{array}$ \\
\hline [36] & $\begin{array}{l}11, \\
\text { male }\end{array}$ & Weeks & $\begin{array}{l}\text { Dex, AmB, Flu, Azithromycin, 5-FC, } \\
\text { Sulfadiazine, pentamidine, } \\
\text { metronidazole }\end{array}$ & On 7th day & 27 days & Died & $\begin{array}{l}\text { Palliative care on day } \\
49\end{array}$ \\
\hline
\end{tabular}

\section{TABLE 6: Use of miltefosine for Balamuthia GAE}

AmB: amphotericin B, Rif: rifampin, Flu: fluconazole, AZM: azithromycin, Dex: dexamethasone, Acy: acyclovir, Van: vancomycin, CFX: ceftriaxone, Deoxy AmB IV: deoxycholate amphotericin B intravenously, TMP-SMX: trimethoprim-sulfamethoxazole, 5-FC: flucytosine, GAE: granulomatous amebic encephalitis

Overall, four case reports were included in this review on GAE caused by Balamuthia. Miltefosine seemed to be the least effective on GAE caused by Balamuthia in comparison to GAE caused by both $\mathrm{N}$. fowleri and Acanthamoeba. Two cases died despite early treatment with miltefosine due to unclear reasons. In contrast, the two cases that survived received miltefosine relatively late. Miltefosine seems to have a beneficial effect 


\section{Conclusions}

Encephalitis caused by free-living amoebas is one of the rarest, yet deadliest, infections that still agitates the medical community in the 21st century. Until today, there are no definitive guidelines to be followed when treating such patients. However, miltefosine has demonstrated promising results. Miltefosine decreases the usual mortality rate in the three infections; however, only a few reports exist due to the low frequency of the infections. The documented cases in our report seem to point out a decrease in the mortality rate as compared to patients treated with standard management. Nonetheless, more research and clinical trials should help set definitive guidelines that can be used worldwide when presented with these life-threatening infections.

\section{Additional Information \\ Disclosures}

Conflicts of interest: In compliance with the ICMJE uniform disclosure form, all authors declare the following: Payment/services info: All authors have declared that no financial support was received from any organization for the submitted work. Financial relationships: All authors have declared that they have no financial relationships at present or within the previous three years with any organizations that might have an interest in the submitted work. Other relationships: All authors have declared that there are no other relationships or activities that could appear to have influenced the submitted work.

\section{References}

1. Yoder JS, Eddy BA, Visvesvara GS, Capewell L, Beach MJ: The epidemiology of primary amoebic meningoencephalitis in the USA, 1962-2008. Epidemiol Infect. 2010, 138:968-975. 10.1017/S0950268809991014

2. Matanock A, Mehal JM, Liu L, Blau DM, Cope JR: Estimation of undiagnosed Naegleria fowleri primary amebic meningoencephalitis, United States. Emerg Infect Dis. 2018, 24:162-164. 10.3201/eid2401.170545

3. Capewell LG, Harris AM, Yoder JS, et al.: Diagnosis, clinical course, and treatment of primary amoebic meningoencephalitis in the United States, 1937-2013. J Pediatric Infect Dis Soc. 2015, 4:68-75. 10.1093/jpids/piu103

4. Visvesvara GS, Moura H, Schuster FL: Pathogenic and opportunistic free-living amoebae: Acanthamoeba spp., Balamuthia mandrillaris, Naegleria fowleri, and Sappinia diploidea. FEMS Immunol Med Microbiol. 2007, 50:1-26. 10.1111/j.1574-695X.2007.00232.x

5. Qvarnstrom Y, Visvesvara GS, Sriram R, da Silva AJ: Multiplex real-time PCR assay for simultaneous detection of Acanthamoeba spp., Balamuthia mandrillaris, and Naegleria fowleri. J Clin Microbiol. 2006, 44:3589-3595. 10.1128/JCM.00875-06

6. Kalra SK, Sharma P, Shyam K, Tejan N, Ghoshal U: Acanthamoeba and its pathogenic role in granulomatous amebic encephalitis. Exp Parasitol. 2020, 208:107788. 10.1016/j.exppara.2019.107788

7. Trabelsi H, Dendana F, Sellami A, Cheikhrouhou F, Neji S, Makani F, Ayadi MA: Pathogenic free-living amoebae: epidemiology and clinical review. Pathol Biol (Paris). 2012, 60:399-405. 10.1016/j.patbio.2012.03.002

8. Reddy R, Vijayasaradhi M, Uppin MS, Challa S, Jabeen A, Borghain R: Acanthamoeba meningoencephalitis in an immunocompetent patient: an autopsy case report. Neuropathology. 2011, 31:183-187. 10.1111/j.14401789.2010.01151.x

9. Marciano-Cabral F, Cabral G: Acanthamoeba spp. as agents of disease in humans . Clin Microbiol Rev. 2003, 16:273-307. 10.1128/CMR.16.2.273-307.2003

10. Petry F, Torzewski M, Bohl J, et al.: Early diagnosis of acanthamoeba infection during routine cytological examination of cerebrospinal fluid. J Clin Microbiol. 2006, 44:1903-1904. 10.1128/JCM.44.5.1903-1904.2006

11. Cope JR, Landa J, Nethercut $\mathrm{H}$, et al.: The epidemiology and clinical features of Balamuthia mandrillaris disease in the United States, 1974-2016. Clin Infect Dis. 2019, 68:1815-1822. 10.1093/cid/ciy813

12. Kalyatanda G, Rand K, Lindner MS, et al.: Rapid, noninvasive diagnosis of Balamuthia mandrillaris encephalitis by a plasma-based next-generation sequencing test. Open Forum Infect Dis. 2020, 7:ofaa189. 10.1093/ofid/ofaa189

13. Ong TYY, Khan NA, Siddiqui R: Brain-eating amoebae: predilection sites in the brain and disease outcome . J Clin Microbiol. 2017, 55:1989-1997. 10.1128/JCM.02300-16

14. Lindsley CW: Torn from the headlines: surviving the 'brain eating amoeba' . ACS Chem Neurosci. 2016, 7:1313. 10.1021/acschemneuro.6b00282

15. Schuster FL, Guglielmo BJ, Visvesvara GS: In-vitro activity of miltefosine and voriconazole on clinical isolates of free-living amebas: Balamuthia mandrillaris, Acanthamoeba spp., and Naegleria fowleri. J Eukaryot Microbiol. 2006, 53:121-126. 10.1111/j.1550-7408.2005.00082.x

16. Cope JR: Investigational drug available directly from $\mathrm{CDC}$ for the treatment of infections with free-living amebae. MMWR Morb Mortal Wkly Rep. 2013, 62:666.

17. Heggie TW, Küpper T: Surviving Naegleria fowleri infections: a successful case report and novel therapeutic approach. Travel Med Infect Dis. 2017, 16:49-51. 10.1016/j.tmaid.2016.12.005

18. Cope JR, Conrad DA, Cohen N, Cotilla M, DaSilva A, Jackson J, Visvesvara G: Use of the novel therapeutic agent miltefosine for the treatment of primary amebic meningoencephalitis: report of one fatal and one surviving case. Clin Infect Dis. 2016, 62:774-776. 10.1093/cid/civ1021

19. Cooper AM, Aouthmany S, Shah K, Rega PP: Killer amoebas. Primary amoebic meningoencephalitis in a changing climate. JAAPA. 2019, 32:30-35. 10.1097/01.JAA.0000558238.99250.4a 
20. Dunn AL, Reed T, Stewart C, Levy RA: Naegleria fowleri that induces primary amoebic meningoencephalitis: rapid diagnosis and rare case of survival in a 12-year-old caucasian girl. Lab Med. 2016, 47:149-154. 10.1093/labmed/lmw008

21. Mushtaq MZ, Mahmood SBZ, Aziz A: A fatal case of primary amoebic meningoencephalitis (PAM) complicated with diabetes insipidus (DI): a case report and review of the literature. Case Rep Infect Dis. 2020, 2020:4925819. 10.1155/2020/4925819

22. Stowe RC, Pehlivan D, Friederich KE, Lopez MA, DiCarlo SM, Boerwinkle VL: Primary amebic meningoencephalitis in children: a report of two fatal cases and review of the literature. Pediatr Neurol. 2017, 70:75-79. 10.1016/j.pediatrneurol.2017.02.004

23. Mrva M, Garajová M, Lukáč M, Ondriska F: Weak cytotoxic activity of miltefosine against clinical isolates of Acanthamoeba spp. J Parasitol. 2011, 97:538-540. 10.1645/GE-2669.1

24. Polat ZA, Obwaller A, Vural A, Walochnik J: Efficacy of miltefosine for topical treatment of Acanthamoeba keratitis in Syrian hamsters. Parasitol Res. 2012, 110:515-520. 10.1007/s00436-011-2515-0

25. Brondfield MN, Reid MJA, Rutishauser RL, et al.: Disseminated Acanthamoeba infection in a heart transplant recipient treated successfully with a miltefosine-containing regimen: case report and review of the literature. Transpl Infect Dis. 2017, 19:e12661. 10.1111/tid.12661

26. Aichelburg AC, Walochnik J, Assadian O, et al.: Successful treatment of disseminated Acanthamoeba sp infection with miltefosine. Emerg Infect Dis. 2008, 14:1743-1746. 10.3201/eid1411.070854

27. Webster D, Umar I, Kolyvas G, et al.: Treatment of granulomatous amoebic encephalitis with voriconazole and miltefosine in an immunocompetent soldier. Am J Trop Med Hyg. 2012, 87:715-718. 10.4269/ajtmh.2012.12-0100

28. Monogue ML, Watson D, Alexander JS, Cavuoti D, Doyle LM, Wang MZ, Prokesch BC: Minimal cerebrospinal fluid concentration of miltefosine despite therapeutic plasma levels during the treatment of amebic encephalitis. Antimicrob Agents Chemother. 2019, 64:1-4. 10.1128/AAC.01127-19

29. Modica S, Miracco C, Cusi MG, et al.: Non-granulomatous cerebellar infection by Acanthamoeba spp. in an immunocompetent host. Infection. 2018, 46:885-889. 10.1007/s15010-018-1231-4

30. Zamora A, Henderson H, Swiatlo E: Acanthamoeba encephalitis: a case report and review of therapy. Surg Neurol Int. 2014, 5:68. 10.4103/2152-7806.132239

31. El Sahly H, Udayamurthy M, Parkerson G, Hasbun R: Survival of an AIDS patient after infection with Acanthamoeba sp. of the central nervous system. Infection. 2017, 45:715-718. 10.1007/s15010-017-1037-9

32. Ahmad AF, Heaselgrave W, Andrew PW, Kilvington S: The in vitro efficacy of antimicrobial agents against the pathogenic free-living amoeba Balamuthia mandrillaris. J Eukaryot Microbiol. 2013, 60:539-543. 10.1111/jeu.12062

33. Martínez DY, Seas C, Bravo F, Legua P, Ramos C, Cabello AM, Gotuzzo E: Successful treatment of Balamuthia mandrillaris amoebic infection with extensive neurological and cutaneous involvement. Clin Infect Dis. 2010, 51:7-11. 10.1086/653609

34. Vollmer ME, Glaser C: A Balamuthia survivor. JMM Case Rep. 2016, 3:1-6. 10.1099/jmmcr.0.005031

35. Yohannan B, Feldman M: Fatal Balamuthia mandrillaris encephalitis. Case Reports in Infectious Diseases. 2019, 2019:9315756. 10.1155/2019/9315756

36. Roy SL, Atkins JT, Gennuso R, et al.: Assessment of blood-brain barrier penetration of miltefosine used to treat a fatal case of granulomatous amebic encephalitis possibly caused by an unusual Balamuthia mandrillaris strain. Parasitol Res. 2015, 114:4431-4439. 10.1007/s00436-015-4684-8 